\title{
De la Transición democrática a la posmodernidad. Propuestas poéticas para una España cambiante ${ }^{1}$
}

\author{
From the democratic transition to postmodernity. Poetic proposals for a \\ changing Spain
}

\author{
Giuliana Calabrese \\ giuliana.calabrese@gmail.com \\ Università degli Studi di Bergamo, Italia
}

Cita sugerida: Calabrese, G. (2020). De la Transición

democrática a la posmodernidad. Propuestas poéticas para una

España cambiante. Olivar, 20(31), e071.

https://doi.org/10.24215/18524478e071

En un capítulo de El arco y la lira, argumentando la necesaria temporalidad de la poesía, Octavio Paz afirma que "el poema es histórico de dos maneras: la primera, como producto social; la segunda, como creación que trasciende lo histórico pero que, para ser efectivamente, necesita encarnar de nuevo la historia y repetirse entre los hombres" ([1956] 2004, pp. 187-188). La cuestión no consiste en asumir los textos literarios como referentes de eventos históricos, sino en leer su relación con los procesos y los cambios de la historia a través de una profundización crítica que tenga presente la dimensión temporal, sociológica, cultural y de mercado de la obra literaria, muy a menudo creando dinámicas de ruptura y restauración (cfr. Paz, 2001) y considerando desde esa perspectiva el concepto de tradición. El movimiento de ruptura con el presente -recuperando el pasado para, en realidad, dirigirse hacia el futuro- es típico de cualquier momento de crisis, entendida esta última como "cambio profundo y de consecuencias importantes en un proceso o en una situación”, según la definición del diccionario académico.

La tradición de la ruptura es [...] profundamente revolucionaria porque no puede institucionalizarse nunca y porque no es susceptible de ser orientada burocráticamente. Incluso cuando los mismos poetas pretenden organizarla [...], la subdivisión en sectas, la polémica intergeneracional y otras formas subalternas de ruptura terminaron por imponerse. (Rodríguez Monegal, 1998, p. 139) 
La producción poética analizada en los dos volúmenes de este monográfico se adscribe al período de profundo cambio de los años de la Transición española a la democracia, tras la muerte de Francisco Franco, y es partícipe de las repercusiones del campo cultural transicional en las poéticas de autores que en su escritura tienen muy en cuenta los primeros pasos de las trayectorias escriturales vinculadas a un período relativamente breve, pero particularmente intenso, de las letras españolas. Junto con las rupturas históricas y políticas fijadas aproximadamente en la década entre el comienzo de la fragmentación estructural de la dictadura franquista y la consolidación del primer gobierno del PSOE, con una democracia hasta aquel momento no del todo afirmada en la psicología nacional (cfr. Vilarós, 2018, p. 38), entre los límites más maleables de las periodizaciones literarias nos encontramos con una clara ruptura estética con respecto al modelo sesentayochista.

$\mathrm{Si}$, desde el punto de vista histórico, pronto el pactismo dejó ver que el cambio político no iba a suponer ninguna ruptura con el modelo del capitalismo liberal que se había venido desarrollando al menos desde los años sesenta, y que las posturas más radicales eran cuidadosamente dejadas a un lado o asumidas por los discursos del continuismo posibilista, en lo literario y en lo social pronto se estableció una conciencia de "desencanto" radical, manifiesta en una pluralidad de expresiones estéticas que en su escepticismo permitían percibir un cierto optimismo utópico, la posibilidad de habitar un no-lugar, que pronto se vio que era el espacio definitorio de la posmodernidad, parejo a la pérdida del sentido de la historia que arrastraba (Lanz, 2008, p. 26).

Dentro de este panorama, para pasar a lo puramente literario, la teoría del complejo de Edipo (cfr. Bloom, 1977) -o, si queremos ser menos freudianos, el principio de ruptura y regeneración-, tiene la ventaja de funcionar bien como categoría pedagógica y promocional, vistos los mecanismos de replanteamiento de las bases de la posmodernidad y una industria cultural cada día más floreciente, tal y como ha ocurrido con la progresiva disidencia dentro de las filas novísimas y el asentamiento de la poética experiencial en el centro del campo cultural de comienzos de los años ochenta.

Teniendo en cuenta el peso de la ruptura o de recuperación de la tradición anterior con respecto a los años de Transición, el objetivo de este monográfico es estudiar algunas de las propuestas estéticas de la época a la luz de la evolución del eje figurativismo/irrealismo, cuya preponderancia fluctúa a lo largo del período. Los puntos de ruptura o la continuidad respecto a los códigos poéticos anteriores pueden interpretarse desde otro punto de vista cambiando la perspectiva desde la linealidad de la progresión temporal hasta la circularidad del campo cultural y de sus líneas de fuerzas, estableciendo por lo tanto una separación casi siempre bien definida entre centro y márgenes (Bourdieu, 2002 [1995]). A partir de la disgregación de la línea experiencial desde la mitad de los años noventa, los modelos polarizados del pasado parecen insuficientes a la hora de transmitir la polifonía poética actual y la visión de campo se revelará muy útil si la aplicamos al estudio de la poesía española de hoy en día, que necesariamente toma como referencia el momento de la Transición y que puede ser entendida como un espacio policéntrico sin las polaridades entre corrientes hegemónicas y menores.

Volviendo a los años transicionales y asumiendo la mirada de campo, el artículo que inaugura el primer apartado de este monográfico nos sitúa en los márgenes de disidencia poética frente al predominio de la estética realista. A través del estudio de algunos poetas de la vertiente de la Transición que él denomina "mágica", Luis Bagué Quílez nos ofrece sus perspectivas de alejamiento de sus respectivos paradigmas generacionales recuperando el adjetivo "mágico" a partir de la misma cualidad con la que, en el ensayo Moratín y la ilustración mágica (1972) de Luis Felipe Vivanco, se nos muestra el lado menos neoclásico del poeta y dramaturgo del siglo XVIII, autor "transicional" entre los últimos racionalistas y los primeros románticos. En la actitud vital quizás más propia de Goya que de Moratín y en su capacidad visionaria de ver hacia lo auténticamente interior de un pueblo -o por lo menos en su voluntad de aquello-, el estudioso formula un interrogante: ¿puede aplicarse una mecánica parecida al momento de la Transición española y a las poéticas más cercanas a la distorsión visual de Goya que a las lógicas más racionalistas de lo figurativo? A un Moratín y a una Ilustración "mágicos" que encerraban lo que pudo haber sido si se hubiesen actualizado muchas de 
las potencias en su interior, Luis Bagué Quílez hace corresponder la hipótesis de "otra" Transición, "que acabaría engullida por una normalización democrática que parecía exigir un 'realismo posmoderno"” (según la definición que el autor recupera de Oleza, 1996). Frente al sociolecto realista que triunfa en la poesía de los ochenta, en este artículo se recopilan poéticas menores que aluden a las circunstancias del momento mediante un lenguaje marginal y códigos simbólicos cercanos a la alegoría (intra)histórica, como es el caso de Primer y último oficio (1978) de Carlos Sahagún o a una indagación en la identidad colectiva, siempre con imágenes de cuño irracional, como en el poemario Un país como éste no es el mio (1978) de José Antonio Gabriel y Galán. Bagué Quílez continúa su argumentación con ejemplos de más poetas que se refugian en sus marginalidades: Juan Ramos, con Teoría y práctica del círculo (1979), el trasmundo onírico de Taller del hechicero (1979) de Aníbal Núñez, y la pulsión alucinatoria que crea un código cercano al neosurrealismo en De una niña deprovincias que se vino a vivir en un Chagall (1981) de Blanca Andreu. Con el conjunto de estos poemarios, se hace más evidente la perspectiva de campo y de archivo culturales: se trata de autores que, a pesar de efímeros momentos de centralidad - como ocurre con el poemario de Blanca Andreu galardonado con el premio Adonais-, se quedan en los márgenes hablándole a la promoción de jóvenes que vive su efervescencia en los años posteriores a la muerte de Franco, y con la aspiración a considerarse como la voz colectiva del sujeto de la época que manifiesta un desarrollo personal en que se trata de dejar atrás la adolescencia para entrar en la juventud, como en el caso de la poeta gallega, o el pasado para adentrarse por fin en el futuro. A pesar de su posición disidente entre las líneas de fuerza poética de la época, siguiendo las palabras de Germán Labrador,

es en el interior de esas estructuras de relaciones donde se lee y se es leído, donde se critica y se es criticado y los autores y los críticos no son entelequias sino sujetos sociales formalizados por su época y por las reglas de esos espacios comunitarios tanto cuando las siguen como cuando las contravienen. Resulta obvio decirlo, pero no lo es tanto asumir las consecuencias de comenzar a pensar a partir de esos parámetros. (Labrador, 2008, pp. 58-59)

Pensando a partir de estos parámetros, Bagué Quílez recuerda con los textos de Sahagún que los años transicionales no se identifican con un "nuevo amanecer sino con un eclipse, como una invitación a mantenernos en guardia ante una Transición fundada en los pactos de silencio”.

Efectivamente, como recuerda Antonio Jiménez Millán, con respecto a la vida social los primeros años ochenta dejan una impresión "de libertad recién estrenada, entre el desenfado y la osadía" (1998, p. 7). Y sin embargo, muchos de los poemarios que aparecieron en aquella época distaban mucho de fomentar el optimismo de la movida, como es el caso de los textos analizados por Luis Bagué Quílez, pero también de la corriente figurativa de la otra sentimentalidad a los que se refiere concretamente Jiménez Millán. Hablando del grupo granadino, señala:

no me parece anecdótica la referencia casi constante a Pier Paolo Pasolini, a esa lucidez un tanto desolada que conducía al distanciamiento, a la elegía por un mundo en ruinas, a una apuesta moral que siempre tuvo en cuenta los signos de la crisis y el bagaje de la historia. Historia leída a través de una ciudad, itinerarios sentimentales que intentaban descifrar el presente, aquellos poemas orientados hacia otro romanticismo (es el título de un poema de Paseo de los tristes, de Javier Egea) hablaban, sobre todo, de la posibilidad de una vida menos sórdida. Muchos de ellos fundaban una memoria personal y colectiva. (Jiménez Millán, 1998, p. 7)

En la incipiente democracia española fue apuntándose progresivamente la necesidad de una poesía atenida a los requerimientos del tiempo histórico, como leemos en las palabras de Jiménez Millán. Con su referencia a Javier Egea y dejando momentáneamente de lado el peso de Pier Paolo Pasolini en los años de la Transición, pasamos al segundo artículo de este monográfico. En él, Fernando Candón Ríos empieza a acercarnos a la centralidad del campo literario de la época con la aparición de la ya mencionada otra sentimentalidad, el grupo granadino que para la tradición poética española supone desde ese momento el fulcro en el que idear un sistema estético adaptado a los nuevos tiempos democráticos y de asentamiento del capitalismo. Nacida como propuesta poética e ideológica elaborada, entre otros, por Luis García Montero, Álvaro Salvador y Javier Egea bajo el magisterio de Juan Carlos Rodríguez, la otra sentimentalidad encuentra en el ideario marxista 
las bases teóricas sobre las que asentar su primera época y sus manifiestos, todavía "en el privilegio de la periferia” (Soria Olmedo, 1998, p. 91). Sin embargo, como señala Candón Ríos, la poética del grupo "no tarda en transformarse en un producto mucho más sencillo y acorde a la ideología dominante”, juntándose con otros arroyos en una confluencia experiencialista que acaba desbordando los diques de la poesía en toda la península (Rodríguez, 1999, p. 21).

Frente a la normalización de las prácticas socialdemocráticas propias del período postmoderno, el trabajo de Candón Ríos subraya la naturaleza de un poemario de Javier Egea, Troppo mare (1984), que se sitúa en los márgenes de estos nuevos tiempos, definiéndolo como el "último refugio contra la postmodernidad". En esta acertada visión y, con las bases teóricas de la otra sentimentalidad, en la contribución se analiza el libro como cuestionamiento de la realidad en tanto que construcción subjetiva, por medio del propio lenguaje; con la poesía como práctica ideológica contra la cultura postmoderna, Troppo mare es un canto al fracaso personal desde la perspectiva empírica del poeta, pero también a la derrota colectiva "en el ocaso de la causa marxista ante la nueva democracia y la postmodernidad", señala Candón Ríos.

En esa dimensión comprometida, aunque con muy distintos matices, coinciden perspectivas muy diferentes, una de las cuales ilustra la rama de la otra sentimentalidad que ha ido ampliando sus márgenes dentro de una estética realista. En esta ideología que confiaba en la construcción histórica de los sentimientos y en las grandes revoluciones colectivas emprendidas desde el ámbito privado creía, por lo menos en sus primeros poemarios, otro gran protagonista de la otra sentimentalidad, Luis García Montero. A lo largo de los años y con una trayectoria consolidada, Luis García Montero se ha convertido en el poeta más representativo de la corriente figurativa surgida a partir de las raíces ideológicas del grupo granadino, llegando a ocupar un lugar central dentro del campo poético de finales de los ochenta y comienzos de los noventa y adquiriendo un gran número de epígonos debido, quizás, a la progresiva democratización del gusto que supuso la poesía de la experiencia y a las lecturas simplificadoras desus versos.

Las reflexiones sobre las premisas ideológicas que sustentaban la creación poética de García Montero en la época de la Transición se recogen en el artículo de Xelo Candel Vila. Pese a la fidelidad hacia su formación ideológica y estética, a partir de su poemario Vista cansada (2008), "algo ha cambiado en el poeta", afirma Candel Vila. Centrándose en dos aspectos de su poética, la memoria lírica del pasado como indagación sobre la intimidad y la defensa del carácter ideológico de la literatura a través de la tradición, en este artículo se aborda la desconfianza que surge en la indagación de la intimidad en los poemarios de García Montero publicados entre 2008 y 2019. Durante la primera época de su escritura, desde ese ya lejano 1979 en que ganó el Premio Federico García Lorca con Y ahora ya eres dueño del puente de Brooklyn, el poeta percibía el problema de la expresión lírica planteado por Machado: "el sentimiento no es una creación del sujeto individual, una elaboración cordial del yo con materiales del mundo esterno [...]. Mi sentimiento no es [...] exclusivamente mío, sino más bien nuestro. Sin salir de mí mismo noto que en mi sentir vibran otros sentires, y que mi corazón canta siempre en coro" (1988, p. 1310). García Montero, y con él los poetas de la otra sentimentalidad, entendían, en los años de Transición, que si la poesía hubiese seguido fundándose en sentimientos considerados erróneamente eternos y universales, entonces la poesía se habría quedado lejos de la historia contingente, sin poder penetrar en el subconsciente colectivo de su propia época ni conectar con el público que vivía unas muy especiales condiciones de vida como las del momento.

Sin embargo -siguiendo con la argumentación de la autora-, el fracaso de los valores democráticos, la crisis económica de 2008, la mercantilización del tiempo, la pérdida de confianza en el discurso público y de cualquier sueño utópico se transmutan en su sentimentalidad privada, favoreciendo la reflexión sobre el intercambio entre el yo y el otro, lo íntimo y lo histórico en poemarios de García Montero como A puerta cerrada (2017), donde se recupera la lección ilustrada y la necesidad de que la poesía pueda ser útil como herramienta de reflexión sobre quiénes somos. En cuanto al segundo de los temas subrayados por Xelo Candel Vila, el peso que sigue teniendo la tradición literaria y sentimental en la etapa más reciente del autor granadino, la autora reivindica en sus últimos libros el firme poder de la palabra poética como compromiso 
social. Candel Vila define Balada en la muerte de la poesía (2016), por ejemplo, como "un alegato a la tradición poética como refugio ante el mundo", subrayando, en este contexto mediatizado por la tecnología, el papel de compromiso que con la realidad contemporánea todavía tiene el humanismo, último reducto contra la mecanización del ser humano. A pesar de la "vista cansada" por los años y las desilusiones y frente a una visión destructiva, la poética de García Montero sigue abogando por la premisa ideológica inicial de sus trabajos críticos, con la ternura como forma de reivindicación.

La lectura dialéctica a medio camino entre intimidad e historia es una lección que, como señala Candel Vila, García Montero aprende de la tradición literaria. A partir de este trabajo nos movemos hacia el artículo de María Payeras Grau para seguir con la continuidad y el diálogo que, en los años de Transición, establecen las poéticas emergentes respecto a la de autores y códigos estéticos anteriores y posteriores, en un espacio de intertextualidad y diálogo intergeneracional.

Recuperando las teorías de Bloom sobre las influencias (1977), es indispensable analizar el juego de fuerzas diseñado en el campo cultural de las estéticas de la Transición y considerar que la Generación del 50, uno de los colectivos de voces poéticas españolas más relevantes del siglo XX (cf. Payeras Grau ed., 2016), constituye uno de los referentes imprescindibles para los autores de la otra sentimentalidad. Esta idea es la que expone Payeras Grau en su contribución, subrayando el tributo rendido a la generación del medio siglo y, en particular, a la poética de Jaime Gil de Biedma por parte de los jóvenes del grupo granadino, tanto en números monográficos de revistas como en las innumerables referencias intertextuales en sus poemarios.

Ofreciendo un profundizado recorrido por las numerosas revistas a las que se conectó la otra sentimentalidad (Tragaluz, Poesía 70, La fábrica del sur, Olvidos de Granada, entre otras) y a los monográficos que se editaron, María Payeras señala que desde las primeras publicaciones, Jaime Gil de Biedma emerge como maestro del joven grupo poético junto a Ángel González, los dos en un rango de honor. Si el tributo al poeta ovetense se debe sobre todo al tono irónico utilizado para abordar la experiencia subjetiva, recuerda Payeras Grau que Gil de Biedma pronto se convierte en el referente teórico principal del grupo gracias a sus reflexiones sobre teoría poética, en las que lleva al lector a desconfiar de la identificación entre autor empírico y sujeto poético. La autora señala, además, que la otra sentimentalidad debe a la generación del medio siglo el logro de recuperar el concepto ilustrado de "representación, [que] toma cuerpo en el interior de la crítica del sujeto tradicional [...] como producción ideológica" (Díaz de Castro, 2003, p. 23), y a Gil de Biedma y a su reflexión sobre The poetry of Experience (Langbaum, 1957) la introducción del concepto de "experiencia" para referirse a poéticas que provoquen una coparticipación de sentimientos surgidos desde una vivencia vinculada al contexto histórico.

En la segunda parte de su investigación, María Payeras analiza las contribuciones en verso en las que más evidentes resultan las referencias intertextuales al poeta barcelonés, cuya lectura dejó huellas profundas no solo en la teoría, sino también en la práctica poética de los jóvenes de la otra sentimentalidad. Los "lugares privilegiados" señalados por la autora son muchos de los poemarios de Luis García Montero, algunos versos de La mala crianza (1978), de El agua de noviembre (1985) o de La condición del personaje (1992) de Álvaro Salvador, unos textos de Poemas del desempleo (1985) de Antonio Jiménez Millán o de La canción del olvido (1985) y de Cámara subjetiva (1996) de Ángeles Mora. Además del recurso irónico, María Payeras rastrea la razón histórica y el "juego de hacer versos" establecidos por el referente biedmiano también en poemarios de Benjamín Prado e Inmaculada Mengíbar, para centrarse después en el análisis detallado de poemas de García Montero, Jiménez Millán y Álvaro Salvador en los que los hipotextos de Jaime Gil de Biedma actúan como espacios compartidos desde los cuales proyectar la intimidad del sujeto en la colectividad histórica.

En torno al diálogo intergeneracional que se produce en las páginas de una publicación periódica se articula también el artículo de José Jurado Morales, que cierra el primer volumen de este monográfico y que se dedica a estudiar la voluntad de Joaquín Márquez, director de la revista sevillana Cal (1974-1979), de apostar por la publicación de escritores que empiezan su andadura en la primera posguerra y cuyas poéticas vinculan los años de la Transición democrática con el pasado y el presente de Sevilla gracias a la incorporación en la 
revista de voces más maduras, como algunos poetas de la Generación del 27 o de su órbita. En el repaso de los números de Cal ofrecido en esta contribución, se aprecia la participación de Vicente Aleixandre, Rafael Laffón, Luis Cernuda, Gerardo Diego, Jorge Guillén y Juan Sierra, entre otros, evidenciando la voluntad de Joaquín Márquez y de sus colaboradores de establecer un vínculo intergeneracional que enlazara el tiempo y la geografía poéticos de Andalucía en las páginas de su revista. Además, la concesión del Premio Nobel de Literatura a Vicente Aleixandre en 1977 puede interpretarse como un galardón colectivo que premia la tarea intelectual de todo este grupo. José Jurado señala en los números de Cal fenómenos transgeneracionales que, al margen de las cuestiones objetivas de la edad, ponen de manifiesto una sensibilidad porosa y especialmente receptiva a las expresiones poéticas circulantes en una generación por parte de poetas pertenecientes a otra; la revista "atesora el mérito de haber contribuido a la revitalización de la poesía sevillana y de haber dado cauce a la creación de poetas muy diversos en los tiempos de la Transición política de los años setenta”, explica Jurado Morales.

En la estela del diálogo entre generaciones poéticas y de la intertextualidad situamos la contribución de Sharon Keefe Ugalde, que abre la segunda parte del monográfico introduciendo además el tema de la emergencia de mujeres poetas que reivindican una nueva condición, alejada de los estereotipos de la posguerra española y acorde con los nuevos tiempos. Como recuerda la autora, "en España, para finales de la década de 1980, las connotaciones negativas de 'poesía femenina' no se habían disipado”; en este contexto, Keefe Ugalde se dedica a analizar el "efecto catalítico" que tuvo la obra de Ángel González en la poesía de Ángeles Mora. El interrogante que se plantea la poeta, miembro de la otra sentimentalidad y, por lo tanto, con la voluntad ideológica de adscribir sus versos a la expresión de la intimidad en el contexto histórico, es cómo transmitir la intensidad emocional "sin tropezar con la pertinaz sombra degradante de poesía femenina", indica Sharon Keefe Ugalde. Su artículo pone de relieve el "método" que Ángeles Mora encuentra en varios procedimientos poéticos de Ángel González para no caer en la etiqueta de sensiblería, como por ejemplo la dicción coloquial e irónica y su función pragmática de acercamiento cómplice del lector, pero a la vez un distanciamiento que "vigila, corrige y contrapesa el tono emotivo con el tono crítico" (Iravedra, 2007, p. 72). En esta contribución, el foco vuelve también en la generación del medio siglo, cuya percepción particular ante los hechos históricos sirve de inspiración para muchos de los poetas figurativos, como se ha visto en el artículo de Payeras Grau y como se subraya en este de Keefe Ugalde.

Con Ángeles Mora no solo recuperamos el peso del vínculo intergeneracional, sino que también regresamos al territorio de centralidad ocupado por la estética realista en la poesía de los ochenta.

Dentro del mismo código dominante en la década y de su clara tendencia realista, aunque a lo largo de su trayectoria se produce un paulatino viraje hacia lo elegíaco que no afecta la organicidad del conjunto (Bianchi, 2014), también Felipe Benítez Reyes elabora una lectura de la representación femenina, como explica María Isabel López Martínez en su artículo abordando el recorrido "de la donna angelicata a la mujer ocasional” en los versos del poeta gaditano. Esta elaboración de la imagen de la mujer se produce muy a menudo por medio de un diálogo poético con la tradición, como pone de manifiesto la autora al recordar que en la época postmoderna el recurso intertextual crea una fundamental complicidad entre el poeta y el lector, recuperando también el concepto de complicidad sentimental tan necesario en la poética experiencial. Entre los referentes que López Martínez señala en los textos seleccionados sobresalen, en primer lugar, los códigos petrarquistas y áureos y su imagen de la mujer inaccesible, pero desde la devoción por este único ser angelical se pasa, gracias a la subversión que la poética experiencial hace de estos tópicos, a construir una sentimentalidad amorosa poblada por una mujer "de quien no se refleja ni siquiera el nombre”, explica María Isabel López con profundas claves hermenéuticas. En las escenas urbanas típicas de la poesía de la experiencia de la primera etapa de Benítez Reyes, "la poesía acepta lo transitorio sin necesitar la quietud consoladora de alguna sublimación", tal como se recuerda en esta contribución con una cita de García Montero. En el entorno de caducidad y cambio, también la palabra es una herramienta fatua, además de desacralizadora, y 
la mujer que transita por la estética realista responde a un perfil heterogéneo sin voz propia pero acorde a la educación sentimental de la época (Sanz, 2016).

Permaneciendo dentro del territorio de la construcción del sujeto femenino en las poéticas de la Transición, pero desde el protagonismo de su voz directa, María Teresa Navarrete nos acompaña en un recorrido por la obra de Clara Janés. En una primera lectura de su poesía, explica Navarrete, no se percibe "que estemos ante literatura sobre la mujer, literatura para la mujer o literatura feminista". Sin embargo, gracias a caminos metodológicos que ahondan en la construcción social del género en contra de los preconceptos culturales sobre el lugar que el sujeto debe ocupar de acuerdo a las diferenciaciones sexuales, María Teresa Navarrete demuestra que la poética de Janés, consolidada en los primeros años del período democrático, se revela especialmente útil para analizar el efecto del cambio histórico que se produce con la Transición. En la novedad de la escritura de Clara Janés, "que en nuestra lengua carece casi de tradición y cuenta" (Siles, 2015 , p. 7) y en su raigambre metafísica, Navarrete rastrea versos y poemas que rompen la burbuja de la esfera silenciada de lo femenino llevándola al debate público, tanto en la poética de Janés como en las obras de muchas autoras de la época. Desde esta perspectiva, en la contribución se analiza el erotismo como un instrumento de exteriorización con el que se supera el límite de la interioridad, recurso especialmente condensado en los poemas de Eros (1981), aunque Navarrete considere que puede apreciarse en la mayoría de los libros de Clara Janés. Después de dar cuenta del conmovedor descubrimiento de Janés del poeta checo Holan, y lejos de querer ponerla en centro del ágora con su búsqueda de lo exterior para mantenerla en cambio en el "abismo de lo ignoto" (Janés, 1999, p. 49), Navarrete sigue explorando la tercera etapa de la poeta centrándose en el libro Kampa (1986). Como un signo más en la conquista de lo exterior, en el poemario "el sujeto lírico supera los límites de la intimidad y, desde la nueva mismidad sustentada en su identidad como mujer, indaga el paisaje cotidiano, se fusiona con otras identidades y experimenta una sexualidad más libre", señala la autora.

A lo largo de este pasaje por lo femenino nos hemos alejado paulatinamente del centro dogmático de la tendencia realista, como se ha podido apreciar. Permanecemos en este territorio independiente y periférico con respecto a los circuitos literarios hegemónicos con la contribución de Blas Sánchez Dueñas, que estudia la obra de la canaria Ana María Fagundo, una "poeta-isla", como se define en el artículo, que plasma en su escritura una "cosmogonía ginocéntrica". En su caso también, los poetas del medio siglo ejercen un papel indispensable en el despertar de su vocación literaria, pero esta vez el referente es la poesía del conocimiento de José Ángel Valente y Enrique Baldosa. Establecidas las bases de su poética, Sánchez Dueñas explora las fases de escritura de Fagundo vertebrando su creación sobre tres claves esenciales y orgánicas: la búsqueda de la identidad, mediada por la palabra como instrumento esencial de proyección del pensamiento; la simbología del paisaje canario, que, como para la mayoría de escritores insulares, pronto adquiere rasgos de "atributos psicogeográficos", según expone el autor; y, por último, la mirada elegíaca hacia el pasado y la constante afirmación de la vida a pesar del vacío y la incomunicación de la postmodernidad. Blas Sánchez Dueñas indica en la segunda fase creativa de Fagundo el punto culminante de su escritura, donde "se adentra en una poética configurada sobre los soportes de su identidad y corporeidad de mujer envueltos en torno al alumbramiento de una cosmogonía ginocéntrica y feminista donde el ser femenino se configura como figura central protagonista tanto en su inmanencia intrínseca corporal e ideológica como en su proyección exterior en relación con el contexto, la naturaleza y la sociedad que la rodea”. Gracias al artículo de Sánchez Dueñas aprendemos que para Ana María Fagundo el origen de la palabra se encuentra en el cuerpo femenino, vehículo del verbo poético que reafirma la pasión por la vida.

Quedando en el territorio de poéticas "cuya misión [es] el destierro" (Milán, 2008, p. 5), una profunda indagación sobre el sujeto poético femenino, a pesar de su singular condición nómada, se produce también en la obra de Olvido García Valdés. Sin embargo, en la contribución "Notas de rodaje” no se quiere ahondar en el territorio femenino, sino que se demuestra la vinculación que la poeta asturiana establece con Pier Paolo Pasolini. Se toma en cuenta, por lo tanto, uno de los factores clave que se producen en el momento 
de la Transición, como es el fenómeno de la internacionalización. La vitalidad desesperada (Pasolini, 1982, p. 133) del poeta italiano es motivo de inspiración para los poetas de estos años, sobre todo para quienes ven en su poética una fuerte referencia ideológica. Una de las claras vertientes social de su obra se expresa en el concepto de "mutación antropológica" (1983, p. 222), elaborado en 1974 y desde una postura que había alcanzado una magnitud filosófica. Su reflexión sobre las devastadoras consecuencias de la industrialización del país, la progresiva influencia de los medios de comunicación y del consumismo desenfrenados surgen de la observación de la industria cultural en un estado europeo que estaba enriqueciéndose después de un pasado opresivo y muy influenciado por la Iglesia católica. Es evidente la referencia a Italia en en la conceptualización de esta situación de parte de Pasolini, pero en su drama Calderón (1973), ambientado en la España de 1967, el poeta italiano elabora en su dialéctica entre individuo y poder un discurso premonitorio que se podría aplicar también a la época de la Transición española y al asentamiento de las dinámicas postmodernas. Desde esta perspectiva de enfrentamiento a la "mutación antropológica" se pueden leer en mi artículo no solo las poéticas más abiertamente ideológicas, sino también la "elegía a lo menor" (Milán, 2008, p. 6) de Olvido García Valdés, elaborada a través de referencias intertextuales surgidas en su producción posterior gracias, precisamente, a la labor de traducción al español de La religión de mi tiempo (1961) de Pasolini.

En la poética de García Valdés, como en la escritura de Ana María Fagundo, la vida arde a pesar de la gravedad de la muerte, de la incomunicabilidad y de la soledad del ser humano, "soledad de lo animal" que García Valdés traspone a sus versos desde la poética pasoliniana, y condición a la que se añade el matiz de materialismo elaborado siempre a partir de los versos del poeta boloñés. La noción de animalidad adquiere en los poemarios de la asturiana la vertiente espacial de límite de lo humano, conformando a la vez una geografía poética del sujeto, que empieza de esta manera a esbozar sus propias fronteras entre interioridad y exterioridad. Dicha separación entre sujeto y espacio no crea categorías estancas, al contrario: la concepción de un yo poético expandido y la superación de la intimidad hacia lo exterior, como hemos visto en el caso de Clara Janés, permite la creación de vínculos con los demás y contribuye en la elaboración de un sujeto femenino transicional que aborda lo material desde otra perspectiva aún con respecto a las poéticas realistas.

Desde los comienzos de su andadura poética, y antes de elaborar el concepto de "mutación antrópológica", también Pasolini concibe la escritura como un acto de vida, de amor desenfrenado por la realidad y la "distancia" entre intimidad y colectividad y entre vida y literatura es un cuestionamiento que, como subrayaba Juan Carlos Rodríguez a propósito de la otra sentimentalidad, se convierte en modelo (junto a los de Bertolt Brecht y Cesare Pavese) para escribir de una manera de tratar la sensibilidad de una forma otra (Rodríguez, 1999, p. 34)

Enriquecida por el mismo matiz arcaico y rural pasoliniano, sobre todo en ella, los pájaros (1994), la escritura de García Valdés está concebida como un retorno al lugar rural, un espacio de ruinas y sobre todo materno, de cuyo fantasma la poeta tendrá que vaciarse para lograr un cuerpo y una palabra propios (Sánchez Moreiras, 2012). Nostálgicos de la matriz, Pasolini y García Valdés vuelven a la pureza de sus raíces con un enfoque fílmico paisajístico que, según se explica en el artículo, la poesía española de la Transición aprende también del poeta italiano y de sus trabajos cinematográficos.

La lateralidad de estas tres últimas poéticas analizadas ha de leerse como "entendimiento de lo poético como espacio de tensión, debate y conflicto que al mismo tiempo es espacio de exploración de lo abierto como resistencia a la sutura de la memoria, de la mirada y del lenguaje" (Canteli, 2014, p. 598).

Gracias al concepto de "sutura" y a la acepción que del término subraya Canteli, nos adentramos en el territorio de la desmemoria en lo cultural con una pulsión de modernidad acelerada que, en su asunción ciega de la lógica publicitaria y mercantil propia del capitalismo tardío, va a rechazar (o cegar) aquellas propuestas que no se plieguen a las exigencias de la sociedad del espectáculo (legibilidad, accesibilidad, productividad, tematización, acriticismo, etc.). La sutura implicaría, entonces, borrar toda posibilidad disidente respecto a esta lógica de desmemoria y mercantilización cultural (Canteli, 2014, p. 598). 
Nos acercamos de esta manera a la contribución que cierra el monográfico desde la fuerza visual, poética e ideológica de Pasolini, que no reverbera solo en las referencias intertextuales en los poemarios de la otra sentimentalidad o en los fotogramas poéticos de García Valdés; también Jorge Riechmann retoma en Poesía practicable (1990) el concepto pasoliniano de "mutación antropológica" para sustentar su idea de transformación social en que se produce la paulatina desaparición del sujeto que representaba la esperanza de la poesía social:

una clase obrera y campesina con tradiciones culturales propias, pobre sin indignidad, portadora de emancipación. Fue masacrada durante la guerra civil y en la represión franquista de la posguerra; fue narcotizada a partir de los años sesenta con la implantación, progresiva y devastadora, de la civilización de consumo de masas. [...] [D]esaparece también aquella burguesía culta 'a lo divino' que constituye otro de los sujetos poéticos fundamentales de nuestra tradición anterior. La voz del poeta se identifica cada vez más con la de un mundo que agoniza. (1990, p. 94)

A la poética de Jorge Riechmann, sobre todo en los poemarios El común de los mortales (2011) y Poemas lisiados (2012), se enfrenta Ambra Cimardi en su artículo, donde acude a las teorías que ahondan en el territorio de la postmodernidad para profundizar el compromiso poético del autor, que desde mediados de los años ochenta integra "la fidelidad a unos principios de raigambre marxista y la indagación en un lirismo descarnado, que ha ido despojándose progresivamente de la matriz simbolista de sus primeros títulos hasta quedar reducido a un humanismo desnudo" (Bagué Quílez, 2006, p. 245).

Ya desde las filas de los postnovísimos antologados por Luis Antonio de Villena (1986), el compromiso asumido por Riechmann no tiene demasiadas expectativas, hecho que Cimardi pone de manifiesto en la lucha del poeta, empezada desde la época de la Transición, contra el sistema tardo-capitalista pero también contra los horrores que a nivel internacional se han vivido a lo largo del siglo XX y poetizados con una mirada retrospectiva y "concéntrica”, como señala la autora retomando una definición de la poesía de Riechmann elaborada por Prieto de Paula (2014).

La trayectoria de Riechmann que Ambra Cimardi establece en su contribución perfila un espacio crítico del autor en que la denuncia social, profundizada desde una perspectiva ecocrítica en los dos últimos poemarios hasta la fecha, se combina con una actitud crítica y una visión escéptica hacia los abusos del poder y las desigualdades cotidianas. A pesar de la instrumentalización del lenguaje contemporáneo y siempre desde una fidelidad hacia lo real, la poética analizada por la autora revela su desconfianza hacia la mirada cortante de un lenguaje desgastado por el uso y por la ideología de violencia dominante y, en cambio, aboga por el compromiso y la responsabilidad de la palabra poética que, "a través de la creación de experiencias, proporciona conocimiento" (Iravedra, 2010, p. 169).

En la realización de este monográfico han participado miembros del grupo $\mathrm{POESCO}^{2}$, junto con destacados especialistas del ámbito español e internacional. En sus estudios encontramos muchas y buenas razones para ahondar en la multiplicidad de evoluciones líricas desprendidas, hasta nuestros días, de la matriz común del momento de la Transición a la Democracia. En el conjunto de artículos que configuran las dos partes de este monográfico y en el esbozo de un campo cultural poético desde el momento de la Transición española que abarcara no solo las estéticas centrales, sino que arrojará luz también sobre las disidencias más periféricas, recordamos lo que señala Cesare Segre reflexionando sobre la historia de la literatura. Cada obra se relaciona con la historia desde una perspectiva diferente, puesto que en cada una de ellas se proyecta la intimidad sentimental de sus autores (Segre, 2001). En la contingencia del fluir histórico, "desobediente una vez más, la poesía trata de hablar del mundo que se manifiesta al alcance de la mano, pero también de aquel que solo late en la desnudez de las palabras" (Prieto de Paula, 2010, p. 48).

\section{ReFERENCIAS}

Bagué Quílez, L. (2006). Poesía en pie de paz. Modos del compromiso hacia el tercer milenio. Valencia: Pre-Textos. 
Bianchi, M. (2014). La trayectoria poética de Felipe Benítez Reyes: entre la experiencia, la elegía y algo más. En J. Jurado Morales (ed.), Felipe Benitez Reyes. La literatura como caleidoscopio (pp. 55-91). Madrid: Visor.

Bloom, H. (1977). La angustia de las influencias. Una teoría de la poesía. Monte Ávila: Caracas.

Bourdieu, P. (2002 [1995]). Las reglas del arte. Génesis y estructura del campo literario. Barcelona: Anagrama.

Canteli, M. (2014). Hacia un afuera: tres poéticas contra la sutura (Ullán, Piera, García Valdés). Revista de Estudios Hispánicos, 48 (3), 597-618.

Díaz de Castro, F. (ed.) (2003). La otra sentimentalidad. Estudio y antología. Barcelona: Fundación José Manuel Lara.

Díez de Revenga, F., Bagué Quílez, L. (2008). Presentación. Monteagudo. Revista de literatura española, hispanoamericana y teoria de la literatura, 13, 13-14.

Iravedra, A. (2007). Poesia de la experiencia. Madrid: Visor.

Iravedra, A. (2010). El compromiso después del compromiso. Poesía, democracia y globalización(poéticas 1980-2005). Madrid: Uned.

Janés, C. (1999). La palabra y el secreto. Madrid: Huerga y fierro.

Jiménez Millán, A. (1998). Introducción. Litoral. Revista de, poesía, arte y pensamiento. Monográfico "Luis García Montero. Complicidades", 217/218, 4-11.

Labrador, G. (2008). Culpables por la literatura. Poéticas e imaginario de la Transición española: campo, discursos, fracturas. Tesis doctoral dirigida por F. Rodríguez de la Flor y S. Lakhdari. Salamanca/París: Universidad de Salamanca/Université de Paris IV-La Sorbonne.

Langbaum, R. (1996 [1957]). La poesía de la experiencia. El monólogo dramático en la tradición literaria moderna. Granada: Comares.

Lanz, J. J. (2008). Luces de cabotaje: la poesía de la transición y la generación de la democracia en los albores del nuevo milenio. Monteagudo. Revista de literatura española, hispanoamericana y teoría de la literatura, 13, 25-48.

Machado, A. (1988). Prosas completas. Ed. O. Macrí, con la colaboración de G. Chiappini. Madrid: Espasa Calpe/ Fundación Antonio Machado.

Oleza, J. (1996). Un realismo posmoderno. Ínsula, 589-590, 39-42.

Pasolini, P. P. (1982). Poesia en forma de rosa (1961-1964). Madrid: Visor.

Pasolini, P. P. (1983). Escritos corsarios. Barcelona: Planeta.

Pasolini, P. P. (1987 [1973]). Calderón. Barcelona: Icaria.

Payeras Grau, M. (ed.) (2016). Fuera de foco. Aproximaciones a la diversidad poética del medio siglo. Madrid: Visor.

Paz, O. ([1956] 2004). El arco y la lira. Madrid: FCE.

Paz, O. (2001). Rupturas y restauraciones. En Obras completas IV: Los privilegios de la vista (pp. 90-104). Barcelona: Galaxia Gutenberg.

Prieto De Paula, A. L. (2010). Poesía en la era de la perplejidad. En Las moradas del verbo. Poetas españoles de la democracia(antologia) (pp. 11-48). Madrid: Calambur.

Prieto De Paula, A. L. (2014). La poesía concéntrica de Jorge Riechmann. Insula, 811-812, 31-34.

Riechmann, J. (1990). Poesía practicable. Apuntes sobre poesia (1984-1988). Madrid: Hiperión.

Rodríguez, J. C. (1999). Dichos y escritos. Sobre la "otra sentimentalidad" y otros textos fechados de poética. Madrid: Hiperión.

Rodríguez Monegal, E. (1998). Tradición y renovación. En C. Fernández Moreno (Ed.), América Latina y su literatura (pp. 139-166). México: Siglo XXI Editores.

Sanz, M. (2016). Éramos mujeres jóvenes. Una educación sentimental de la Transición española. Barcelona: Planeta.

Segre, C. (2001). La storia della letteratura, problema aperto. En Ritorno alla critica (pp. 161-176). Turín: Einaudi.

Siles, J. (2015). Introducción. En C. Janés, Movimientos insomnes. Antologíapoética (1964-2014) (pp.7-39). Barcelona: Galáxia Gutenberg. 
Soria Olmedo, A. (1998). Sentimientos fechados. Litoral. Revista de, poesía, arte y pensamiento. Monográfico "Luis Garcia Montero. Complicidades", 217/218, 91-92.

Vilarós, T. M. (2018). El mono del desencanto. Una crítica cultural de la Transición española. Madrid: Siglo XXI.

Villena, L. A. de. (1986). Postnovisimos. Madrid: Visor.

\section{Notas}

1 Este trabajo se halla vinculado al Proyecto de Investigación del Plan Estatal "Poéticas de la Transición (1973-1982)", ref. FFI2017-84759-P (AEI/FEDER, UE).

2 En el momento actual y de acuerdo con los objetivos del proyecto de I+D "Poéticas de la Transición (1973-1982)" Ref. FFI2017-84759-P (AEI/FEDER, UE), del Programa Estatal de Investigación Científica y Técnica de Excelencia, la labor del grupo se centra en el estudio de los poetas activos durante el período de la Transición española (https://w ww.poesco.es). 